\title{
Surgical treatment of tricuspid valve insufficiency promotes early reverse remodeling in patients with axial-flow left ventricular assist devices
}

\author{
Simon Maltais, MD, PhD, ${ }^{\mathrm{a}}$ Yan Topilsky, MD, ${ }^{\mathrm{a}}$ Vakhtang Tchantchaleishvili, MD, \\ Stephen H. McKellar, MD, MSc, ${ }^{a}$ Lucian A. Durham, MD, PhD, ${ }^{\text {a }}$ Lyle D. Joyce, MD, PhD, ${ }^{\text {a }}$ \\ Richard C. Daly, MD, ${ }^{a}$ and Soon J. Park, MD, MSc ${ }^{\mathrm{a}}$
}

\begin{abstract}
Objective: The HeartMate II (Thoratec Corp, Pleasanton, Calif) continuous-flow left ventricular assist device has emerged as the standard of care for patients with advanced heart failure. The objective of this study was to assess the safety and early effectiveness of concomitant tricuspid valve procedures in patients undergoing implantation of a HeartMate II device.
\end{abstract}

\begin{abstract}
Methods: From February 2007 to April 2010, 83 patients underwent HeartMate II left ventricular assist device implantation. Of these, 37 patients had concomitant tricuspid valve procedures ( 32 repairs, 5 replacements) for severe tricuspid regurgitation. The effects of a tricuspid valve procedure on tricuspid regurgitation and right ventricular remodeling were assessed comparing echocardiographic findings at baseline and 30 days after left ventricular assist device implantation. Overall survival was also compared.
\end{abstract}

\begin{abstract}
Results: Patients undergoing a concomitant tricuspid valve procedure had more tricuspid regurgitation (vena contracta, $5.6 \pm 2.1 \mathrm{~mm}$ vs $2.9 \pm 2.0 \mathrm{~mm} ; P<.001$ ), worse right ventricular dysfunction (right ventricular end-diastolic area, $33.6 \pm 6.2 \mathrm{~mm}$ vs $31.6 \pm 8.5 \mathrm{~mm} ; P=.05)$, higher mean right atrial pressure $(17.4 \pm$ $7.1 \mathrm{~mm} \mathrm{Hg}$ vs $14.9 \pm 5.1 \mathrm{~mm} \mathrm{Hg} ; P=.03)$, and a higher Kormos score $(2.6 \pm 2.1$ vs $1.2 \pm 1.4 ; P=.0008)$ preoperatively. One month after surgery, tricuspid regurgitation was worse in patients who underwent left ventricular assist device implantation alone $(+18.6 \%)$, whereas it improved significantly in patients undergoing a concomitant tricuspid valve procedure $(-50.2 \%)(P=.005)$. A corresponding significant reduction in right ventricular end-diastolic area $(33.6 \% \pm 6.2 \%$ vs $30.1 \% \pm 9.7 \% ; P=.03)$ and a trend toward better right ventricular function $(55.5 \% \pm 79.7 \%$ vs $35.7 \% \pm 60.5 \% ; P=.28)$ were noted in patients undergoing a concomitant tricuspid valve procedure. Survival was comparable between the 2 groups.
\end{abstract}

Conclusions: In patients with severe tricuspid regurgitation undergoing left ventricular assist device implantation, a concomitant tricuspid valve procedure effectively reduces tricuspid regurgitation and promotes reverse remodeling of the right ventricle. (J Thorac Cardiovasc Surg 2012;143:1370-6)

Supplemental material is available online.

Left ventricular assist device (LVAD) implantation is a wellestablished therapy for patients with end-stage congestive heart failure for both the indications of bridge to

From the Department of Surgery/Division of Cardiovascular Surgery, ${ }^{\mathrm{a}}$ Mayo Clinic College of Medicine, Rochester, Minn; and Department of Surgery, ${ }^{\mathrm{b}}$ University of Minnesota, Minneapolis, Minn.

Disclosures: Authors have nothing to disclose with regard to commercial support.

Presented at the 31st annual meeting and scientific sessions of the International Society for Heart and Lung Transplantation, San Diego, California, April 13-16, 2011.

Received for publication March 28, 2011; revisions received June 28, 2011; accepted for publication July 13, 2011; available ahead of print Aug 12, 2011.

Address for reprints: Soon J. Park, MD, MSc, Division of Cardiovascular Surgery, Mayo Clinic, 200 First Street SW, Rochester, MN 55905 (E-mail: park.soon@ mayo.edu).

0022-5223/\$36.00

Copyright (C) 2012 by The American Association for Thoracic Surgery

doi:10.1016/j.jtcvs.2011.07.014 transplantation (BTT) and destination therapy (DT). ${ }^{1-3}$ Patients with advanced heart failure often present in biventricular failure, but the primary cause of heart failure is in the left ventricle in the majority of patients. Clinically, LVAD implantation alone effectively relieves symptoms in the majority of patients. However, a variable degree of residual right ventricular (RV) dysfunction and tricuspid regurgitation (TR) persists after LVAD implantation. Topilsky and colleagues ${ }^{4}$ recently demonstrated the importance of RV reserve remodeling in determining the longterm survival after continuous-flow LVAD implantation. We postulated that concomitant surgical correction of moderate to severe TR at the time of LVAD implantation would be important in promoting RV reverse remodeling and restoring overall survival comparable to those without significant TR. This study compared 2 groups of patients undergoing implantation of a HeartMate II (Thoratec Corp, Pleasanton, Calif) continuous, axial-flow LVAD: those with and without a concomitant tricuspid valve 


$$
\begin{aligned}
& \text { Abbreviations and Acronyms } \\
& \begin{aligned}
\text { BTT } & =\text { bridge to transplantation } \\
\text { DT } & =\text { destination therapy } \\
\text { LV } & =\text { left ventricular } \\
\text { LVAD } & =\text { left ventricular assist device } \\
\text { RV } & =\text { right ventricular } \\
\text { TR } & =\text { tricuspid regurgitation } \\
\text { TV } & =\text { tricuspid valve } \\
\text { TVP } & =\text { tricuspid valve procedure } \\
\text { VC } & =\text { vena contracta }
\end{aligned}
\end{aligned}
$$

procedure (TVP). The objectives of this study were to assess the effectiveness of a concomitant TVP on TR volume, the subsequent RV geometry change, and the overall survival.

\section{MATERIALS AND METHODS \\ Study Population}

Institutional review board approval from the Mayo Foundation for Education and Research (Mayo Clinic, Rochester, Minn) was obtained with an exception granted for obtaining study-specific consent. Demographic and clinical information were obtained from our prospectively collected, institutional LVAD database. This study included the Mayo Clinic's consecutive experience with the HeartMate II continuous-flow device. All other device types were excluded from this study. The patients were divided into 2 groups for comparison based on whether a concomitant TVP was performed or not at the time of LVAD implantation. We calculated and compared groups for clinical scores reported by Lietz and colleagues, ${ }^{5}$ Matthews and colleagues, ${ }^{6}$ and Kormos and colleagues. ${ }^{7}$

\section{Surgical Technique}

We defined a TVP as either TV repair or replacement (Table 1). The majority of repairs consisted of placement of a flexible annuloplasty band or modified Kay annuloplasty stitch with or without De Vega repair. ${ }^{8,9}$ One patient had a posterior-septal leaflet reconstruction secondary to implantable cardioverter defibrillator lead entrapment combined with a modified Kay annuloplasty (Figure 1), and one patient had a septal leaflet repair by placing Gore-Tex neochordae (WL Gore and Associates, Flagstaff, Ariz). If leaflet pathology existed to the extent that annuloplasty would not correct TR, the tricuspid valve was replaced with a bioprosthesis. The Biocor bioprosthetic (St Jude Medical, St Paul, Minn) was used for all patients requiring concomitant TV replacement in this study.

\section{Echocardiographic Assessment}

Echocardiographic examinations were performed in all patients included in this study. The results presented in this study reflect early echocardiographic analysis. All evaluations were performed within 1 month before surgery (median, 16 days), and postoperative echocardiographic results were measured within 30 days (mean, 17 days) after LVAD implantation. Preoperative hemodynamic catheterizations were also obtained. Twodimensional transthoracic echocardiography was performed using the Sonos 5500 (Phillips Medical Systems, Andover, Mass), Sequoia 512 (Siemens Medical Solutions USA, Inc, Mountain View, Calif), or Vivid 7 (GE Medical Systems, Milwaukee, Wis) as described. ${ }^{10-12}$ Right atrial pressure was estimated by the inferior vena cava diameter and its response to inspiration. ${ }^{13} \mathrm{RV}$ function, TR, and mitral regurgitation severity were quantitatively graded using a 4-point scale ( severe $=4$, moderate $=3$, mild $=2$, and trivial or normal $=1)$. The severity of TR was assessed using color flow imaging and vena contracta (VC) width. ${ }^{14} \mathrm{RV}$ function was further described using tissue Doppler assessment of lateral tricuspid annular motion ${ }^{15}$ and the RV index of myocardial performance. ${ }^{16}$

\section{Definition of Terms}

The operative mortality was defined as death from any cause within 30 days of LVAD implantation or during the same hospitalization. RV failure was defined as the need for inotropic support for more than 14 days postoperatively or implantation of an RV assist device.

\section{Statistical Analysis}

Descriptive statistics for categoric variables are reported as frequency and percentage, and continuous variables are reported as mean (standard deviation) or median (range) as appropriate. In this study, patients with a concomitant TVP were compared with patients undergoing LVAD implantation alone. Variables were compared using the chi-square or Kruskal-Wallis tests when appropriate, and continuous variables were compared using a 2-sample $t$ test or Wilcoxon rank-sum test. All 83 patients were included in the analysis.

For each end point, Kaplan-Meier method was used to draw freedomfrom-event curves and calculate freedom-from-event statistics. The software used for analysis was JMP version 8.0 (SAS Institute Inc, Cary, NC).

\section{RESULTS}

\section{Patients}

Between February 2007 and June 2010, we identified 83 consecutive patients who had a HeartMate II continuousflow LVAD (Thoratec Corporation, Pleasanton, Calif) implanted for DT or BTT. Thirty-four patients underwent a concomitant TVP, and the remaining 49 patients underwent LVAD implantation alone. The echocardiographic studies were completed in $100 \%$ of patients, and preoperative right heart hemodynamic studies were completed in 80 patients $(96.4 \%)$.

\section{Preoperative Baseline Characteristics}

The preoperative baseline characteristics of patients are shown in Table 2. Results are expressed for the entire patient population $(n=83)$ and compared for patients with and without a TVP. The mean age was $62.9 \pm 12.0$ years, and $81.3 \%$ were men. Patients undergoing concomitant tricuspid interventions were more likely to be in New York Heart Association functional class IV ( $71 \%$ vs $55 \%$; $P=.02)$, to require a preoperative intraaortic balloon pump ( $44 \%$ vs $27 \% ; P=.03$ ), or to have had prior sternotomy $(56 \%$ vs $47 \% ; P=.006)$ than patients without a TVP. All other clinical, hemodynamic, and laboratory characteristics were comparable between groups $(P>.05)$. Preoperative clinical scores revealed comparable risks between the 2 groups. However, Kormos score indicated a significantly higher risk of RV failure postimplantation for patients undergoing a TVP $(2.6 \pm 2.1$ vs $1.2 \pm 1.4 ; P=.0008)$.

\section{Surgical Data and Tricuspid Valve Procedure}

The details of TV replacement or repairs are summarized in Table 1. The majority of TVPs were repairs. Simple 
TABLE 1. Tricuspid valve procedures

\begin{tabular}{lr}
\hline \multicolumn{1}{c}{ Tricuspid valve procedures $(\mathbf{n}=\mathbf{3 4})$} & $\mathbf{n}$ \\
\hline Repairs (28) & 15 \\
$\quad$ Kay annuloplasty alone & 1 \\
De Vega annuloplasty alone & 6 \\
Kay + De Vega annuloplasty & 1 \\
Partial ring annuloplasty & 3 \\
Annuloflex (Carbomedics, Austin, Tex) $34 \mathrm{~mm}$ & 1 \\
Annuloflex (Carbomedics) 36 mm & \\
Other & 1 \\
Gore-Tex (WL Gore and Associates, & \\
$\quad$ Flagstaff, Ariz) neochordae (septal leaflet) + Kay & $1 / 1 / 4$ \\
$\quad$ Reconstruction septal leaflet + Kay & \\
Replacements (6) & \\
$\quad$ Biocor (St Jude Medical, St Paul, Minn) $29 / 31 / 33 \mathrm{~mm}$ & \\
\hline
\end{tabular}

modified Kay annuloplasty sutures placed at the commissure between septal and posterior leaflets with pledgeted 4-0 Prolene were effective in reducing TR. In some patients with more pronounced TV annular dilatations, the De Vega or flexible annuloplasty bands were added. A more complex TV leaflet repair or placement of Gore-Tex neochordae was performed in a minority of patients. The additional time required for a TVP was approximately 20 minutes on cardiopulmonary bypass support. In this study, all surgeries were performed without aortic crossclamping.

\section{Preoperative Echocardiographic Data}

Table 3 shows preoperative echocardiographic and LVAD parameters. For most parameters estimating left ventricular (LV) systolic function and filling pressures, there were no significant differences between the 2 groups. Preoperative LV end-systolic diameter was smaller for patients in the TVP group $(57.7 \pm 10.6 \mathrm{~mm}$ vs $63.6 \pm 7.6 \mathrm{~mm} ; P=.01)$. When considering RV parameters, there were significant differences between groups. The RV end-diastolic and endsystolic areas were both significantly higher for the TVP group $(33.6 \pm 6.2 \mathrm{~mm}$ vs $30.1 \pm 9.7 \mathrm{~mm}, P=.05$; and $25.3 \pm 5.6 \mathrm{~mm}$ vs $21.6 \pm 8.0 \mathrm{~mm}, P=.02$ ). The observed preoperative right atrial pressure was higher for patients in the TVP group $(17.4 \pm 7.1 \mathrm{~mm} \mathrm{Hg}$ vs $14.0 \pm 6.1 \mathrm{~mm} \mathrm{Hg}$; $P=.03$ ). As expected, TR and TR VC were more pronounced in the TVP group $(3.7 \pm 1.9 \mathrm{~mm}$ vs $1.6 \pm 1.5$ $\mathrm{mm}, P<.001$; and $5.6 \pm 2.1 \mathrm{~mm}$ vs $2.9 \pm 2.0 \mathrm{~mm}, P<.001)$.

\section{Postimplant Echocardiographic Data Assessment}

After LVAD implantation, there were significant echocardiographic differences between the 2 groups (Table E1). As expected, patients in the TVP group had a significant reduction in TR grade and TR VC (TR VC change, $-50.2 \%$ ). TR VC actually worsened in patients without a TVP after LVAD implantation (TR VC change, $+18.6 \%$ ). A favorable effect of TR surgery on RV geometry was documented in
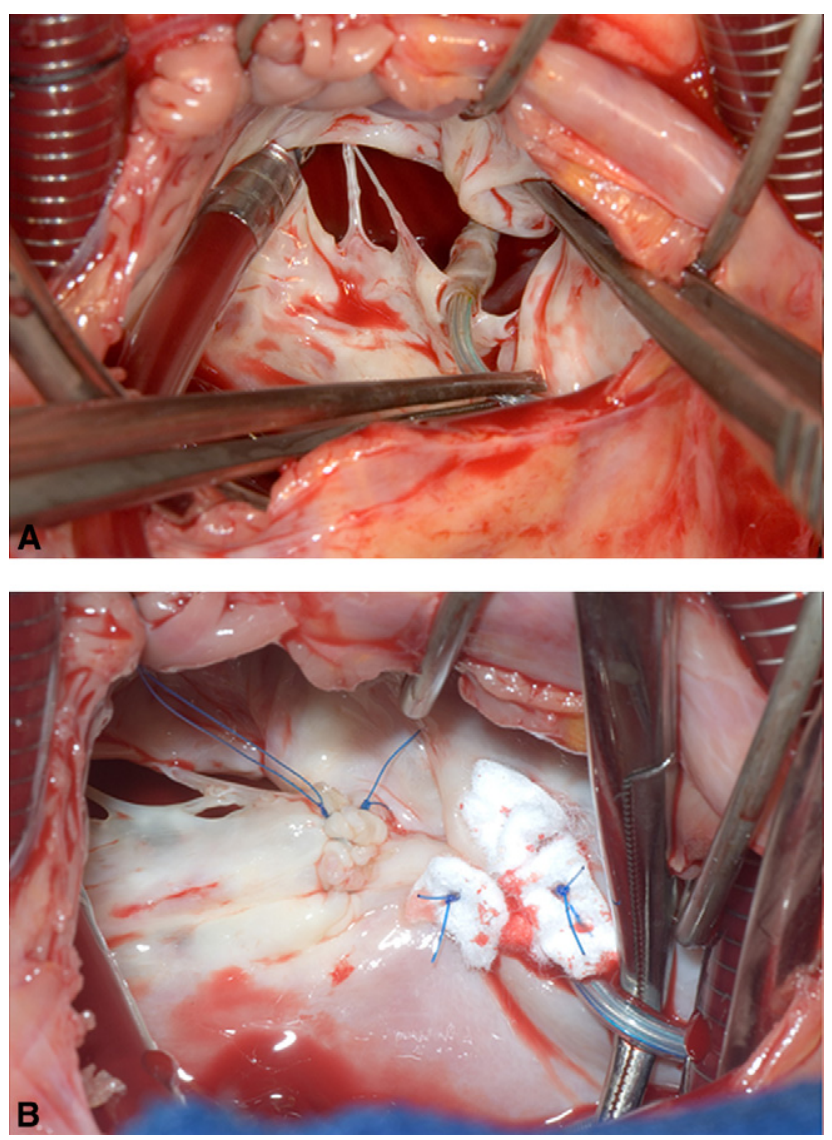

FIGURE 1. Concomitant TV repair during implantation of a HeartMate II device (Thoratec Corp, Pleasanton, Calif) using a modified Kay stitch. A, Severe TR resulted from scattered adhesions between the implantable cardioverter defibrillator lead and the septal leaflet of the TV. B, The valve leaflet was carefully cut to free the implantable cardioverter defibrillator lead. The remaining edges were reapproximated using 5-0 Prolene sutures. The implantable cardioverter defibrillator lead was placed at the commissure between the septal and posterior leaflets. A 4-0 Prolene suture was placed to plicate the tricuspid annulus at the posteroseptal commissure to reduce the effective annulus of the TV (modified Kay stitch).

the TVP group. The RV end-diastolic area and endsystolic area change (reduction) were more pronounced compared with patients with no TR intervention $(-33.6 \%$ $\pm 6.2 \%$ vs $-30.1 \% \pm 9.7 \%, P=.03$; and $-23.4 \% \pm$ $20.0 \%$ vs $-9.0 \% \pm 28.2 \%, P=.02$ ). Although there was a trend toward a more pronounced RV function recovery in patients with a concomitant TVP, RV fractional area contraction and right index of myocardial performance change did not reach statistical significance $(+55.5 \% \pm 79.7 \%$ vs $+35.7 \% \pm 60.5 \%, P=.28$; and $+23.0 \% \pm 52.4 \%$ vs $+38.6 \% \pm 41.7 \%, P=.30)$.

\section{Clinical Outcomes}

Postoperative complications are outlined in Table 4. Although patients were sicker in the TVP group before 
TABLE 2. Baseline characteristics and operative details of all patients stratified by tricuspid valve procedure

\begin{tabular}{|c|c|c|c|c|}
\hline & $\begin{array}{l}\text { All patients } \\
\quad \mathbf{n}=\mathbf{8 3}\end{array}$ & $\begin{array}{c}\text { TVP } \\
\mathbf{n}=\mathbf{3 4}\end{array}$ & $\begin{array}{c}\text { No TVP } \\
n=49\end{array}$ & $P$ value \\
\hline Age (y) & $62.9 \pm 12.0$ & $64.0 \pm 12.0$ & $61.6 \pm 12.7$ & .38 \\
\hline Men/women (\%) & $81.3 / 18.1$ & $70.6 / 29.4$ & $89.8 / 10.2$ & $.03 *$ \\
\hline \multicolumn{5}{|l|}{ NYHA functional class } \\
\hline IIIb & 40 & 29 & 45 & \multirow[t]{2}{*}{$.02 *$} \\
\hline IV & 60 & 71 & 55 & \\
\hline Prior sternotomy (\%) & 51 & 56 & 47 & $.006^{*}$ \\
\hline Preoperative IABP (\%) & 31 & 44 & 27 & $.03 *$ \\
\hline Preoperative inotropic use $(\%)$ & 74 & 78 & 72 & .55 \\
\hline DT $(\%)$ & 67 & 71 & 61 & .60 \\
\hline \multicolumn{5}{|l|}{ Type of cardiomyopathy } \\
\hline Ischemic heart disease & 54 & 50 & 52 & \multirow[t]{4}{*}{.84} \\
\hline Dilated cardiomyopathy & 34 & 41 & 33 & \\
\hline Restrictive heart disease & 10 & 6 & 12 & \\
\hline Other & 2 & 3 & 3 & \\
\hline Mean heart rate (beats/min) & $77.1 \pm 14.0$ & $76.1 \pm 16.2$ & $78.0 \pm 13.9$ & .58 \\
\hline Mean systolic blood pressure (mm Hg) & $99.4 \pm 14.0$ & $99.3 \pm 13.7$ & $99.5 \pm 15.2$ & .95 \\
\hline Mean diastolic blood pressure $(\mathrm{mm} \mathrm{Hg})$ & $62.4 \pm 10.0$ & $62.2 \pm 11.7$ & $66.0 \pm 9.3$ & .15 \\
\hline Hemoglobin $(g / d L)$ & $11.8 \pm 2.0$ & $11.4 \pm 1.9$ & $12.2 \pm 1.8$ & .06 \\
\hline PVR (Woods units) & $4.2 \pm 3.0$ & $4.4 \pm 3.0$ & $3.5 \pm 3.0$ & .20 \\
\hline Bilirubin (mg/dL) & $1.2 \pm 0.7$ & $1.3 \pm 0.8$ & $1.2 \pm 0.7$ & .57 \\
\hline BUN (mg/dL) & $31.0 \pm 16.0$ & $33.2 \pm 18.5$ & $29.5 \pm 15.1$ & .87 \\
\hline Creatinine (mg/dL) & $1.3 \pm 0.5$ & $1.3 \pm 0.4$ & $1.3 \pm 0.5$ & .94 \\
\hline NT-BNP (pg/mL) & $5.7 \pm 5.2$ & $6.5 \pm 6.6$ & $5.6 \pm 5.2$ & .60 \\
\hline Albumin & $3.7 \pm 0.8$ & $3.7 \pm 0.6$ & $3.8 \pm 0.5$ & .35 \\
\hline INR & $1.4 \pm 0.4$ & $1.4 \pm 0.4$ & $1.4 \pm 0.4$ & .95 \\
\hline Leitz-Miller score & $9.7 \pm 5.7$ & $9.8 \pm 5.9$ & $9.6 \pm 5.7$ & .59 \\
\hline Matthews score & $1.34 \pm 1.9$ & $1.9 \pm 3.0$ & $0.9 \pm 1.8$ & .09 \\
\hline Kormos score & $1.9 \pm 1.9$ & $2.6 \pm 2.1$ & $1.2 \pm 1.4$ & $.0008 *$ \\
\hline
\end{tabular}

NYHA, New York Heart Association; DT, destination therapy; IABP, intraaortic balloon pump; $P V R$, pulmonary vascular resistance; $B U N$, blood urea nitrogen; INR, international normalized ratio; $N T$-BNP, N-terminal brain natriuretic peptide. *Statistically significant difference between TVP vs no TVP groups.

LVAD implantation, postoperative complication rates were comparable between the 2 groups. The early incidence of $\mathrm{RV}$ failure and the need for a postoperative RV mechanical support were comparable between the no TVP and TVP groups $(26 \%$ vs $36 \%, P=.51 ; 4 \%$ vs $6 \%, P=.69)$. A trend toward increased operative mortality was noted in the TVP group $(16.6 \%$ vs $4.1 \%, P=.07)$, but the overall survivals were comparable (Figure 2).

\section{DISCUSSION}

Widely approved as BTT or DT, the HeartMate II device is used with increased frequency because it is easy to implant and has been associated with a significant improvement in survival and durability. ${ }^{1-3}$ Few series have studied the surgical results of a concomitant TVP or the early effect of a continuous-flow LVAD on RV remodeling and TR. ${ }^{10,17,18}$ Short-term results from Maeder and colleagues ${ }^{17}$ have reported a trend toward beneficial RV remodeling demonstrated by a reduction in the tricuspid annulus plane systolic excursion. However, they failed to demonstrate a significant improvement in RV fractional area shortening
4 months after LVAD implantation. Lee and colleagues ${ }^{18}$ recently proposed an early (3-6 months) favorable effect of the HeartMate II device in the improvement of RV function.

Nevertheless, severe TR and significant RV dysfunction have consistently been identified as preoperative predictors of poor RV function and high mortality after LVAD implantation. ${ }^{19-21}$ In contrast with the LV, RV function recovery is fully dependent on the degree of LV unloading and associated decrease in pulmonary artery pressures. In addition, RV failure post-LVAD implantation can be precipitated by multiple causes, including the acute development of postoperative pulmonary artery hypertension, alterations in mechanical relationship between the RV and the "unloaded" LV, or further impairment of RV contractility after inadequate myocardial preservation during surgery or superimposed nonrevascularized territory. ${ }^{18}$ On the other hand, Frazier and colleagues ${ }^{22}$ have raised significant concerns regarding RV function and axial-flow devices, proposing that the nonphysiologic leftward shift of the interventricular septum could lead to progressive RV dysfunction. 
TABLE 3. Echocardiographic, catheterization, and left ventricular assist device parameters

\begin{tabular}{|c|c|c|c|c|}
\hline & All & TVP & No TVP & $P$ value \\
\hline \multicolumn{5}{|l|}{ LV parameters } \\
\hline LV diastolic diameter (mm) & $67.2 \pm 9.0$ & $65.4 \pm 10.1$ & $68.5 \pm 9.0$ & .15 \\
\hline LV systolic diameter $(\mathrm{mm})$ & $60.8 \pm 9.0$ & $57.7 \pm 10.6$ & $63.6 \pm 7.6$ & $.01 *$ \\
\hline Ejection fraction $(\%)$ & $19.7 \pm 7.0$ & $18.3 \pm 6.0$ & $20.9 \pm 10.2$ & .18 \\
\hline \multicolumn{5}{|l|}{ LV diastolic parameters } \\
\hline Left atrial volume (mL) & $133.0 \pm 39.0$ & $127.4 \pm 35.7$ & $137.7 \pm 57.7$ & .40 \\
\hline E-wave velocity $(\mathrm{m} / \mathrm{sec})$ & $1.0 \pm 0.4$ & $1.1 \pm 0.5$ & $1.0 \pm 0.3$ & .26 \\
\hline E-wave deceleration time (msec) & $135.9 \pm 30.0$ & $133.4 \pm 35.4$ & $137.3 \pm 27.7$ & .65 \\
\hline E/e' ratio & $27.5 \pm 12.0$ & $27.1 \pm 10.3$ & $27.8 \pm 12.8$ & .79 \\
\hline \multicolumn{5}{|l|}{ RV parameters } \\
\hline $\mathrm{RV}$ end-diastolic area $\left(\mathrm{cm}^{2}\right)$ & $31.6 \pm 8.5$ & $33.6 \pm 6.2$ & $30.1 \pm 9.7$ & $.05^{*}$ \\
\hline $\mathrm{RV}$ end-systolic area $\left(\mathrm{cm}^{2}\right)$ & $23.2 \pm 7.3$ & $25.3 \pm 5.6$ & $21.6 \pm 8.0$ & $.02 *$ \\
\hline RV fractional area $(\%)$ & $0.3 \pm 0.1$ & $0.3 \pm 0.1$ & $0.29 \pm 0.1$ & .08 \\
\hline RV ejection time corrected (s) & $302.8 \pm 38.8$ & $305.6 \pm 45.7$ & $300.4 \pm 31.9$ & .60 \\
\hline Tricuspid annulus end-systolic diameter (cm) & $3.7 \pm 0.7$ & $3.71 \pm 0.5$ & $3.7 \pm 0.6$ & .72 \\
\hline TV ejection time (ms) & $466.9 \pm 69.1$ & $449.6 \pm 76.5$ & $481.7 \pm 59.1$ & $.04 *$ \\
\hline Estimated RA pressure (mm Hg) & $14.9 \pm 5.1$ & $17.4 \pm 7.1$ & $14.0 \pm 6.1$ & $.03 *$ \\
\hline Mean pulmonary pressure $(\mathrm{mm} \mathrm{Hg})$ & $36.1 \pm 9.3$ & $36.2 \pm 8.6$ & $36.0 \pm 9.9$ & .90 \\
\hline Wedge pressure $(\mathrm{mm} \mathrm{Hg})$ & $23.4 \pm 7.3$ & $23.7 \pm 6.7$ & $23.4 \pm 7.1$ & .85 \\
\hline $\mathrm{RA} /$ wedge ratio & $0.7 \pm 0.3$ & $0.8 \pm 0.3$ & $0.6 \pm 0.3$ & .11 \\
\hline Preoperative RIMP & $0.6 \pm 0.2$ & $0.5 \pm 0.2$ & $0.6 \pm 0.2$ & .09 \\
\hline TV lateral annulus velocity $(\mathrm{m} / \mathrm{sec})$ & $0.1 \pm 0.1$ & $0.1 \pm 0.1$ & $0.09 \pm 0.03$ & .71 \\
\hline RV functional grade $>$ moderate $(\%)$ & 50 & 30 & 32 & .10 \\
\hline \multicolumn{5}{|l|}{ LVAD parameters } \\
\hline Pump speed (rpm) & $9425 \pm 250$ & $9462 \pm 320$ & $9504 \pm 254$ & .58 \\
\hline Pump flow discharge (L/min) & $5.2 \pm 0.7$ & $5.2 \pm 0.6$ & $5.2 \pm 0.7$ & .63 \\
\hline LVAD inflow pulsatility index & $5.0 \pm 0.7$ & $4.9 \pm 0.7$ & $5.0 \pm 0.7$ & .54 \\
\hline
\end{tabular}

$R A$, Right atrial; RIMP, right index of myocardial performance. *Statistically significant difference between TVP vs no TVP groups.

This study was conducted to investigate the early consequences of continuous-flow mechanical circulatory support on TR and to assess the effectiveness of a TVP in patients with moderate to severe TR. The present study has several unique features compared with previously published studies: (1) The series comprises a large surgical population with or without a TVP in a contemporary population with an axial-flow LVAD; (2) the surgical procedure is closely associated to echocardiographic data and focuses on several right-sided parameters known to be important in early RV function and recovery, TR severity, and RV remodeling; and (3) early survival and surgical outcomes are compared between patients with or without a TVP.

\section{Effect of Simple Concomitant Tricuspid Regurgitation Procedure}

As other groups have proposed, ${ }^{22,23}$ our study demonstrated a possible early unfavorable effect of continuous-flow physiology on mild to moderate TR because an early significant increase in TR VC was observed in patients in the no TVP group $(+18.6 \%)$. In patients in the TVP group who survived implantation, we confirmed the early effectiveness of a TVP by demonstrating a significant reduction in TR VC (TR VC change, $-50.2 \% ; P=.005$ compared with the no TVP group). Compared with patients with no TVP, patients in the TVP group demonstrated RV geometry changes that were consistent with reverse remodeling and improved RV function. Although patients in the TVP group represented a sicker patient population with more RV dysfunction at baseline, the overall survival and incidence of postoperative complications and RV failure requiring RV assist device implantation or prolonged inotropic support were comparable between the 2 groups. Simple and effective surgical corrective strategies, such as the Kay, De Vega, or partial band annuloplasty, resulted in significant improvement of TR. Although more challenging, these concomitant repairs were all performed with a minimal increase in cardiopulmonary bypass time $(115.8 \pm 30.9$ minutes vs $94.4 \pm 33.6$ minutes; $P=.006$ ). This finding is in contradiction with recently published results by Saeed and colleagues, ${ }^{24}$ who showed without echocardiographic data that a concomitant TVP in patients with severe TR significantly prolonged operative time and did not change outcomes. However, recent reports suggest that significant TR is an important marker for RV dilatation and dysfunction; its presence before LVAD implantation signals a greater risk of RV failure after LVAD implantation 
TABLE 4. In-hospital or 30-day complications after left ventricular assist device implantation in patients with or without a tricuspid valve procedure

\begin{tabular}{|c|c|c|c|c|}
\hline & All & TVP & No TVP & $P$ value \\
\hline Cardiopulmonary bypass time ( $\mathrm{min}$ ) & $103.3 \pm 34.0$ & $115.8 \pm 30.9$ & $94.4 \pm 33.6$ & $.006^{*}$ \\
\hline Infection $(\%)$ & 49 & 36 & 57 & .06 \\
\hline Acute cerebral event $(\%)$ & 12 & 15 & 8 & .32 \\
\hline Prolonged intubation $(\%)$ & 23 & 27 & 20 & .47 \\
\hline Acute renal failure $(\%)$ & 16 & 15 & 16 & .87 \\
\hline Dialysis $(\%)$ & 10 & 18 & 7 & .16 \\
\hline Hepatic dysfunction $(\%)$ & 18 & 21 & 16 & .58 \\
\hline Arrhythmias $(\%)$ & 20 & 15 & 22 & .41 \\
\hline Early hemolysis $(\%)$ & 2 & 1 & 3 & .51 \\
\hline Pump flow (L/min) & $5.1 \pm 0.7$ & $5.6 \pm 0.9$ & $5.3 \pm 0.8$ & .28 \\
\hline RV failure $>$ moderate $(\%)$ & 24 & 26 & 36 & .51 \\
\hline Mean RA pressure $(\mathrm{mm} \mathrm{Hg})$ & $12.8 \pm 5.4$ & $14.7 \pm 5.3$ & $11.5 \pm 5.1$ & $.02 *$ \\
\hline Mean PAP $(\mathrm{mm} \mathrm{Hg})$ & $26.8 \pm 7.2$ & $28.8 \pm 9.0$ & $25.3 \pm 5.0$ & .09 \\
\hline Need RVAD $(\%)$ & 4 & 6 & 4 & .69 \\
\hline Duration inotropic support (h) & $197 \pm 274$ & $207 \pm 286$ & $191 \pm 270$ & .80 \\
\hline Prolonged inotropic support (\%) & 13 & 15 & 12 & .75 \\
\hline 30-d mortality $(\%)$ & 9.6 & 17.6 & 4.1 & .07 \\
\hline Hospital LOS (d) & $21 \pm 14$ & $23 \pm 16$ & $20 \pm 12$ & .46 \\
\hline
\end{tabular}

$L O S$, Length of stay; $P A P$, pulmonary artery pressure; $R A$, right atrial; $R V A D$, right ventricular assist device. *Statistically significant difference between TVP vs no TVP groups

and potential need for RV assist device support. ${ }^{25}$ Likewise, Dreyfus and colleagues ${ }^{26}$ clearly showed that tricuspid repair is beneficial not only in reducing TR but also in decreasing RV volume, which may help improve overall RV performance. ${ }^{26}$

In view of our experience of a concomitant TVP at the time of LVAD implantation, we recommend an aggressive surgical approach to address moderate to severe TR in patients undergoing implantation of an axial-flow LVAD. According to our surgical results, a concomitant TVP is

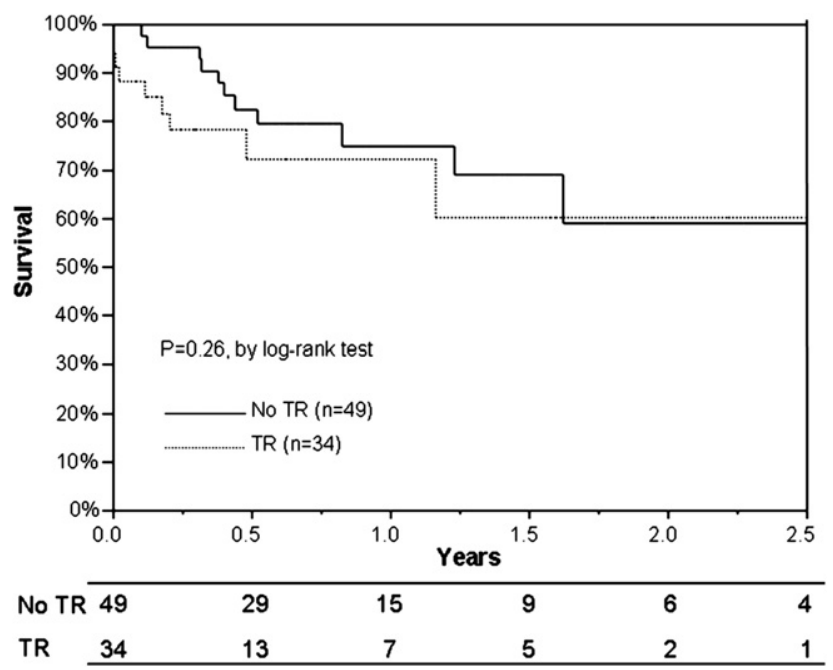

FIGURE 2. Kaplan-Meier estimate of survival in patients with or without a TVP. Kaplan-Meier estimate comparing patients with or without a concomitant TVP at the time of the HeartMate II device implantation. $T R$, Tricuspid regurgitation. effective in reducing TR and positively altering RV geometry. This observation of a TVP possibly having a positive impact on RV function may be of significant importance. In patients awaiting heart transplantation, a TVP could be beneficial to optimize RV reverse remodeling and facilitate patient management; whereas in patients with DT implantations, a concomitant TVP could be performed to optimize functional and survival outcomes.

\section{Limitations}

This study was retrospective and not randomized. All patients with moderate to severe TR over the study period were aggressively treated with repair or replacement. Thus, conclusions on the impact of LVAD implantation alone on significant TR are hard to draw. There are several controversies regarding the impact of LVAD implantation alone on moderate to severe TR. A National Institutes of Health-sponsored randomized trial may help determine whether a TVP would have a positive impact on clinical outcomes and survival. However, in most cases, a relatively simple procedure can be performed quickly, without cardioplegic arrest. In this study, a concomitant TVP not only reduced TR but also improved RV remodeling. Another limitation of this study is that echocardiographic followups were not performed as part of a protocol, but rather were obtained when clinically indicated. Finally, other echocardiographic parameters, such as the degree of eccentricity of the TR immediately pre- and postbypass, were not evaluated. Such measures could be used to assess the initial response of the tricuspid valve to LVAD implantation and guide the surgeon's decision to address residual TR. 


\section{CONCLUSIONS}

In patients with mild to moderate TR, the early changes associated with an axial-flow physiology worsen the degree of TR in patients with no TVP. At the time of LVAD implantation, performing a concomitant TVP using simple repair techniques or a TV replacement in patients with more advanced RV dysfunction leads to improvement in TR, early RV remodeling, and possibly RV function. Despite a higher preoperative calculated risk of RV failure in patients undergoing a TVP, postoperative complications and early survival were comparable between groups. We therefore propose an aggressive TR surgical reducing strategy in patients with more than moderate TR at the time of HeartMate II LVAD implantation. Promoting early RV reverse remodeling is important, especially in the era of DT. Given the exploratory nature of the results, validation in larger patient cohorts is still required.

\section{References}

1. Rose EA, Gelijns AC, Moskowitz AJ, et al. Long-term use of a left ventricular assist device for end-stage heart failure. N Engl J Med. 2001;345:1435-43.

2. Slaughter MS, Rogers JG, Milano CA, et al. Advanced heart failure treated with continuous-flow left ventricular assist device. N Engl J Med. 2009;361: 2241-51.

3. Miller LW, Pagani FD, Russell SD, et al. Use of a continuous-flow device in patients awaiting heart transplantation. $N$ Engl J Med. 2007;357:885-96.

4. Topilsky Y, Oh JK, Shah DK, Boilson BA, Schirger JA, Kushwaha SS, et al. Echocardiographic predictors of adverse outcomes after continuous left ventricular assist device implantation. JACC Cardiovasc Imaging. 2011;4:211-22.

5. Lietz K, Long JW, Kfoury AG, et al. Outcomes of left ventricular assist device implantation as destination therapy in the post-REMATCH era: implications for patient selection. Circulation. 2007;116:497-505.

6. Matthews JC, Koelling TM, Pagani FD, Aaronson KD. The right ventricular failure risk score a pre-operative tool for assessing the risk of right ventricular failure in left ventricular assist device candidates. J Am Coll Cardiol. 2008;51:2163-72.

7. Kormos RL, Teuteberg JJ, Pagani FD, et al. Right ventricular failure in patients with the HeartMate II continuous-flow left ventricular assist device: incidence, risk factors, and effect on outcomes. J Thorac Cardiovasc Surg. 2010;139:1316-24.

8. De Vega NG, De Rabago G, Castillon L, Moreno T, Azpitarte J. A new tricuspid repair. Short-term clinical results in 23 cases. J Cardiovasc Surg (Torino). 1973;Spec No:384-6.

9. Kay JH, Mendez AM, Zubiate P. A further look at tricuspid annuloplasty. Ann Thorac Surg. 1976;22:498-500.

10. Topilsky Y, Tribouilloy C, Michelena HI, Pislaru S, Mahoney DW, EnriquezSarano M. Pathophysiology of tricuspid regurgitation: quantitative Doppler echocardiographic assessment of respiratory dependence. Circulation. 2010; 122:1505-13.

11. Topilsky Y, Maltais S, Oh JK, et al. Focused review on transthoracic echocardiographic assessment of patients with continuous axial left ventricular assist devices. Cardiol Res Pract. 2011;2011:187434.

12. Lang RM, Bierig M, Devereux RB, et al. Recommendations for chamber quantification: a report from the American Society of Echocardiography's Guidelines and Standards Committee and the Chamber Quantification Writing Group, developed in conjunction with the European Association of Echocardiography, a branch of the European Society of Cardiology. J Am Soc Echocardiogr. 2005; 18:1440-63.

13. Kircher BJ, Himelman RB, Schiller NB. Noninvasive estimation of right atrial pressure from the inspiratory collapse of the inferior vena cava. Am J Cardiol. 1990;66:493-6

14. Zoghbi WA, Enriquez-Sarano M, Foster E, et al. Recommendations for evaluation of the severity of native valvular regurgitation with two-dimensional and Doppler echocardiography. J Am Soc Echocardiogr. 2003;16:777-802.

15. Hammarstrom E, Wranne B, Pinto FJ, Puryear J, Popp RL. Tricuspid annular motion. J Am Soc Echocardiogr. 1991;4:131-9.

16. Tei C, Dujardin KS, Hodge DO, et al. Doppler echocardiographic index for assessment of global right ventricular function. J Am Soc Echocardiogr. 1996;9: 838-47.

17. Maeder MT, Leet A, Ross A, Esmore D, Kaye DM. Changes in right ventricular function during continuous-flow left ventricular assist device support [corrected]. J Heart Lung Transplant. 2009;28:360-6.

18. Lee S, Kamdar F, Madlon-Kay R, et al. Effects of the HeartMate II continuousflow left ventricular assist device on right ventricular function. J Heart Lung Transplant. 2010;29:209-15.

19. Dang NC, Topkara VK, Mercando M, et al. Right heart failure after left ventricular assist device implantation in patients with chronic congestive heart failure. J Heart Lung Transplant. 2006;25:1-6.

20. Kavarana MN, Pessin-Minsley MS, Urtecho J, et al. Right ventricular dysfunction and organ failure in left ventricular assist device recipients: a continuing problem. Ann Thorac Surg. 2002;73:745-50

21. Berman M, Tsui S, Vuylsteke A, Klein A, Jenkins DP. Life-threatening right ventricular failure in pulmonary hypertension: RVAD or ECMO? J Heart Lung Transplant. 2008;27:1188-9.

22. Frazier OH, Delgado RM 3rd, Kar B, Patel V, Gregoric ID, Myers TJ. First clinical use of the redesigned HeartMate II left ventricular assist system in the United States: a case report. Tex Heart Inst J. 2004;31:157-9.

23. Frazier OH. Outpatient LVAD: its time has arrived. Ann Thorac Surg. 1994;58: 1309-10.

24. Saeed D, Kidambi T, Shalli S, et al. Tricuspid valve repair with left ventricular assist device implantation: is it warranted? J Heart Lung Transplant. 2011;30: 530-5.

25. Piacentino V III, Williams ML, Depp T, et al. Impact of tricuspid valve regurgitation in patients treated with implantable left ventricular assist devices. Ann Thorac Surg. 2011;91:1342-7.

26. Dreyfus GD, Corbi PJ, Chan KM, Bahrami T. Secondary tricuspid regurgitation or dilatation: which should be the criteria for surgical repair? Ann Thorac Surg. 2005;79:127-32. 
TABLE E1. Echocardiographic changes after left ventricular assist device implantation in patients with or without a tricuspid valve procedure

\begin{tabular}{lccc}
\hline & TVP & No TVP & $P$ value \\
\hline TR > moderate (\%) & 12 & 24 & .42 \\
Postoperative TR VC & $2.5 \pm 1.7$ & $2.6 \pm 1.9$ & .89 \\
TR VC change (\%) & $-50.2 \pm 38.1$ & $+18.6 \pm 120.9$ & $.005 *$ \\
RVFAC change (\%) & $+55.5 \pm 79.7$ & $+35.7 \pm 60.5$ & .28 \\
RIMP change (\%) & $23.0 \pm 52.4$ & $38.6 \pm 41.7$ & .30 \\
RVEDA change (\%) & $-33.6 \pm 6.2$ & $-30.1 \pm 9.7$ & $.03 *$ \\
RVESA change (\%) & $-23.4 \pm 20.0$ & $-9.0 \pm 28.2$ & $.02 *$ \\
\hline RIMP, Right index of myocardial performance; $R V E D A$, right ventricular end-diastolic area; $R V E S A$, right ventricular end-systolic area; $R V F A C$, right ventricular fractional area
\end{tabular}

